\title{
The Assessment of Access to and Utilization of Agricultural Information on Bread Wheat by Smallholder Farmers of Gedab Hasasa District, West Arsi Zone, Oromia Regional State, Ethiopia
}

\author{
Lelisa Daba Chibsa ${ }^{1}$ Genemo Fitala Feyissa ${ }^{2}$ \\ 1.Department of Rural Development and Agricultural Extension, College of Agriculture and Natural resource, \\ Madda Walabu University, P.O. Box 247, Robe, Ethiopia \\ 2.Department of Economics, College of Business and Economics, Madda Walabu University, P.O.Box 247, \\ Robe, Ethiopia
}

\begin{abstract}
This study seeks to determine access to and utilization of agricultural Information on Wheat bread by smallholder farmers of Gedab Hasasa district. The study was motivated by the fact that benefits of agricultural information communication development still need to be known among rural smallholder farmers in the district. It is also not effectively communicated to farmers especially in rural areas although access to and utilization modern information technology is largely available. This paper will examine the relevance of AIs to the rural farmers in Ethiopia. The objectives of the study are to assess the status of access and utilization of agricultural information of rural farmers in Gedab Hasasa district; to identify the constraints faced by farmers to access and utilization of agricultural information to rural farmers and to determine the relation between dependent and independent variables. The sample size was 138 respondents. Random sampling was used in identifying the respondents. A questionnaire was used to solicit responses from the respondents. Data was analyzed using descriptive statistics. As a descriptive statistic, frequency, percentage, minimum, maximum, and range was used. In relation to statistical tests, one-way ANOVA, F-value, Chi-square and spearman's rho were applied. Data was analyzed using SPSS and presented in tables. From the study, except Age all explanatory variables were positively significant relation with information access and utilization categories of the farmers. One of the major challenges to access to AIs was lack of awareness, inadequacy of facilities or professional and DAs biasness in the area. The others, such as lack of credit services, lack of money (Unaffordable price of inputs) and untimely delivery of agricultural inputs was the main constraints to utilized accessed information among the farmers. It was therefore, recommended the need for government, NGOs and public intervention to provide appropriate extension services, to improve DAs capacity through training and create conducive work environment and also establish training sectors for the rural farmers to access the agricultural information as well as to strength the capacity of the existing rural financial institutions and establishing new financial institution, encouraging the farmers to participate in cooperative organization and others local organization to increase accessed information utilization of the farmers.
\end{abstract}

Keywords: Agricultural information, access, utilization, bread wheat production package, smallholder farmers, Ethiopia.

DOI: $10.7176 / J I E A / 10-4-01$

Publication date:September $30^{\text {th }} 2020$

\section{INTRODUCTION}

Ethiopia is the largest country in the Horn of Africa and the second-most-populous nation in Sub-Saharan Africa. With a population of 84 million in 2012, and gross domestic product (GDP) per capita of less than US\$400, it is one of the poorest countries in the world, ranking close to the bottom of the UN Human Development Index (174 out of 179 countries) in 2011 (UNDP, 2011).

The economy is based on agriculture, which contributes $41 \%$ of the total GDP and provides $80 \%$ of the nation's employment. The major agricultural export crop is coffee, providing approximately $30.6 \%$ of Ethiopia's foreign exchange earnings in 2010-11, down from $65 \%$ a decade earlier due to the increase in other exports (US State Department, 2012). Access to ICTs in the rural areas of Ethiopia is constrained both by limited network coverage and a low level of electricity penetration - which stood at 17\% in 2011 (Ethiopian Government, 2012). Lwoga (2010) stated that, improved knowledge and information flows, to, from and within the agricultural sector, are key features in improving small scale agricultural production thus leading to improved livelihoods and high quality of yields. Thus, as the world advances towards a global knowledge economy access to modern Information and Communication Technology and its effective utilization to improve and sustain agricultural production throughout the world has become critical (Collence .T., 2012). Several studies in Africa show that adoptions of improved agricultural technologies, though variably and incompletely, had positive impacts on income, food security and poverty reduction (e.g. Wanyama, et al 2010; Solomon et al 2010, Kassie, et al 2010).

Ethiopia is the second-largest wheat producer in Sub-Saharan Africa next to South Africa. Wheat is one of the major staple crops in the country in terms of both production and consumption. In terms of caloric intake, it is 
the second most important food in the country behind maize (FAO, 2014). Wheat is mainly grown in the highlands of Ethiopia, planted in the summer before the main rainy season, and harvested in October-November. Of the current total wheat production area, about75 percent is located in the Arsi, Bale and Shewa wheat belts (MOA, 2012). There are two varieties of wheat grown in Ethiopia: durum 60\%and bread wheat 40\% (Bergh et al., 2012).

As being one of the largest wheat producers in Africa, the average yield per ha of wheat in Ethiopia is 1712.76 $\mathrm{kg} / \mathrm{ha}$, which is lower than the least developed countries and world average, 1814.67 and $2933 \mathrm{~kg} / \mathrm{ha}$, respectively (IFPRI, 2011). Whereas, Ethiopia's huge potential in wheat production remains unexploited, the country is a net importer of the commodity (Rashid, 2010). This indicates that, the current level of wheat production in Ethiopia is insufficient to meet the domestic consumption needs.

Gedeb Hsasa Woreda is the target area of this study, which is one of the 12 Woredas in Western Arsi Zone of Oromia Regional State, Ethiopia where Wheat is the major and leading crop produced and relatively commercial crop of the district. Furthermore, as the study area is one of the areas where suitable for wheat production, access and utilization of information in wheat production can have a substantial impact to improve the lives of many small farm households.

Although, Grain yields are relatively low due to the country's rugged topography, small-scale landholdings, limited mechanization, and insufficient supplies of fertilizer and improved seed. With the aim of increasing production efficiency and improving the livelihoods of the rural population, the government of Ethiopia along with the Agriculture Transformation Agency (ATA) and the international donor community are working together to address those challenges in order to achieve the GTP goals of raising productivity, intensifying market-oriented agriculture, and promoting increased private investment in the agriculture sector.

Despite such efforts, Ethiopian farmers in general and particular in Gedab Hasasa district have been continued with their traditional way of farming practice. Furthermore, in most cases, farmers differ in their access to and utilization of agricultural information from extension service could be related to various personal, social, economic, institutional and psychological factors.

Therefore, understanding the status of access and utilization of agricultural information by the farmers of the study area and to identify factors influencing it will help the local planer to develop and implement appropriate local development policies to address local problems.

\subsection{Statement of the Problem}

In agriculture, the role of information in enhancing agricultural development cannot be over emphasized. Bachhav (2012) stated that, the use of information in agriculture sector is enhancing farming productivity in a number of ways. The advancements in the Information and Communication Technologies (ICTs) provide an opportunity for developing countries to harness and utilize information and knowledge to improve productivity in various sectors including agriculture (Lwoga, 2010).

Lack of dissemination of information across the agricultural supply chain is a major concern in the developing world. Furthermore, limited coverage of extension services across rural regions and challenges in adapting technology packages to community-specific contexts have also been highlighted as critical issues in the delivery of extension advisory services (IFPRI- World Bank 2010). The study also indicates that, dis-adoption of improved seed-fertilizer package over time, due to high costs, insufficient credit, poor input distribution problem and seeding rate, and lack of improved varieties with traits appropriate to farmers' needs. Diseases and weeds were also the factors explaining relatively low wheat yields (Bogale et al., 2011; Tadesse et al., 2010).

Furthermore, according to GHARDO 2014/15 data, out of the total cultivated land for crop production by smallholders, $60 \%$ of the study district was covered by wheat. In contrast to a high yield potential for wheat production, the smallholder farmers in the study area were frequently faced lower yields below the researchers' suggestions and the standards. This indicates that, wheat production, productivity is low and farmers in the study area are inefficient.

Most rural areas in the district lack information on wheat production package and management practices because of bad road network, poor enabling environment, interconnectivity and high costs of inputs with insufficient/ inadequate knowledge, of (user friendliness of the technologies) is the problem which makes the extension service become inefficient. Also, information delivery is not integrated with target beneficiary to address the numerous related problems that face smallholder in production systems. Despite the agricultural technologies that have been generated through in district is yet to be felt in inefficiency in communicating and sharing agricultural information and knowledge among smallholder farmers.

\subsection{Objectives of the Study}

The general objective of the study is to assess farmers' access to and utilization of agricultural information on bread wheat and to identify factors affecting access to and utilization of agricultural information on bread wheat production package by smallholder farmers of the study area. The specific objectives are:

1. To measure the level of access to and utilization of agricultural information on bread wheat 
production package by smallholder farmers; and

2. To find out the constraints in the access to and utilization of agricultural information among the farmers.

3. To find out the association between access to and utilization of agricultural information with independent variables.

\section{LITRETURE REVIEW}

\subsection{Review of Access to and Utilization of Agricultural Information}

The advancements in the Information and Communication Technologies (ICTs) provide an opportunity for developing countries to harness and utilize information and knowledge to improve productivity in various sectors including agriculture (Lwoga, 2010).

Information makes one to take appropriate decisions on any problem facing him or her at any particular time (Achugbue, 2011). Information can be described as knowledge needed to answer some questions faced by people in their daily lives. Every person needs information for decision-making. Such information ranges from common physiological needs to individual physiological needs. Stressing the importance of information, Wulystan (2012) described information as the cornerstone of successful socio-economic development because it plays a key role in decision-making. Achugbue and Anie (2011) opined that information, as an enterprise is important for the production process especially for agricultural production and marketing of agricultural produce. The major sources of information for farmers were predominantly local (neighbors, friends and family), followed by public extension services. Agricultural input suppliers, village meetings, farmer groups, and co-operative union's and NGOs were important sources of agricultural knowledge in some locations. Print materials with the exception of books had low use due to their unavailability and illiteracy. Apart from radio and cell phones, advanced technologies (i.e. internet and e-mail) were also used at a low rate despite their existence in the communities.

Farmer's access to different information sources helps them to get information about improved technologies and enhance the adoption of new innovations. Conducting various extension events plays an important role in the provision of different agricultural information and consequently enhances the utilization of the accessed information.

Socio-economic characteristics of a farmer such as farm size, farming experience, on-farm and off-farm income and educational level influence the adoption of technologies (Daniel, 2008). Farmer's decision to adopt a new agricultural technology in preference to old technologies depends on factors such as access to institutional services and in-put supply of agricultural technologies (Khan et al., 2008). Resource endowment is also one of the factors affecting farmers' decision to adopt a new agricultural technology (Khan et al., 2008). The ability of farmers to adopt technologies requires financing so as to improve production. A study by Gundu (2006), found that the smallholder farmers lack economic capability to access and utilize relevant agricultural information

In a study conducted by Daniel (2008), on Access and Utilization of Agricultural Information by Resettler Farming Households in Metema Woreda, North Gondar, it was found that, settlement category, education level, settlement orientation, innovation proneness, production motivation, age of household head, frequency of market visits and credit access had influence on the access to and utilization of agricultural information. The study underlined the importance of well-organized agricultural information provision and utilization of information through the delivery of credit and technologies based on the farmer's problem and need.

Studies conducted by Bekele (2008) and Daniel (2008) indicated that, distance from market had negative but significant relationship with access to and utilization of agricultural information. This implies that the more distant farmers are located from the market centers; the lower the likelihood of accessing information and utilize it. Similar study carried out by Yealembirhan (2007), proximity to markets showed positive relationships with the use of modern cultivar wheat seed at the farm level.

Katungi (2006) indicated that social capital is measured by five indicators, each capturing a different aspect of social interaction: the size of the social network, the frequency of interaction in social institutions and civic engagement. Access to extension services is a key determinant in the adoption and use of improved technologies and farming practices (Ebrahim, 2006). Therefore, the frequency of extension contact has an important role in the access to and utilization of agricultural information. Mass media includes electronic such as radio, television and internet and print like newspapers, magazines, posters and extension brochures (Abubakar, 2007). Mass media plays a great role in provision of agricultural information in shortest possible time over a large area (Tadesse, 2008).

\subsection{Constraint of access and utilization of agricultural information}

Ferris (2005) argues that in most African countries lack of accurate and relevant agricultural information by smallscale farmers is a major factor constraining efforts to improve the agriculture sector. Several Challenges facing farmers in accessing agricultural information have been identified. For instance, Tologbonse et al. (2008) found that challenges facing farmers in accessing agricultural information were outdated information, language barrier, 
lack of awareness on existence of different information sources, lack of funds to acquire information and poor format of information carrier. Furthermore, the study by Daudu (2009) pointed out some of the problems encountered by farmers in Nigeria in accessing agricultural information. These include financial problems, inadequacy of facilities or professional, incomplete or irrelevant information. Also, Byamugisha et al. (2008), point out the challenges encountered by farmers in Uganda when searching for agricultural information as lack of cooperation from fellow farmers in sharing agricultural information and language barriers.

Farmer's decision to adopt a new agricultural technology in preference to old technologies depends on factors such as access to institutional services and in-put supply of agricultural technologies (Khan et al., 2008). Agricultural information can only be properly exploited by smallholder farmers who have certain levels of formal literacy. Farmers with basic education are more likely to adopt new technology, and become more productive. Education enhances the ability to derive, decode and evaluate useful information for agricultural production (Jemal, 2010). Resource endowment is also one of the factors affecting farmers' decision to adopt a new agricultural technology (Khan et al., 2008). The ability of farmers to adopt technologies requires financing so as to improve production. Earnings from off-farm and on-farm activities provide ready cash for input purchases as well as other household needs. Lack of access to credit and savings services for farmers in many rural areas limit their ability to purchase needed agricultural technology input. A study by Gundu (2006), found that the smallholder farmers lack economic capability to access and utilize relevant agricultural information. Katungi (2006) indicated that social capital is measured by five indicators, each capturing a different aspect of social interaction: the size of the social network, the frequency of interaction in social institutions and civic engagement.

Furthermore, a study by Odini (2014) pointed out that identifying an information need is the first step towards satisfying information needs and that the information seeking process involves a number of steps before identifying information sources and needed information. Researcher suggested that information systems in Africa were developed without consultation of rural people, thus smallholder farmers lack their awareness and appropriateness. As a result they have inappropriate collections of services that do not address their information needs. Moreover, access, efficiency and affordability of agricultural information are the major barriers in the farming system to uplift agricultural productivity among smallholder farmers (Murithii, 2009). Similarly, agricultural knowledge and information system for rural development and sustainable agriculture links farmers and institutions to promote mutual learning and generate, share, and utilize agricultural technologies, information and knowledge to change rural livelihoods (FAO, 2010). Similarly, Babu et al. (2011) conducted a study on farmers' information needs and search behaviors in Tamil Nadu. The findings from this study showed that the major constraints facing farmers in accessing information were poor availability, poor reliability, lack of awareness of information sources available among farmers and untimely provision of information. Additionally, Mtega and Benard (2013) carried out the study on the state of rural information and communication services in Tanzania. The findings from the referred study show that, poor or unreliable information infrastructure, high illiteracy levels, low income, lack of electricity and high cost of ICTs have limited the accessibility of information services in rural areas.

The idea of Kantumaya (1992 as quoted by Ofuoku, 2008) supports this point by stating information as power which an individual in every society should have access to. It also means evolving strategies for overcoming barriers to utilization of information, understanding information needs, and designing information delivery systems. The decision making process in agriculture rests squarely on information available to farmers, ranchers, entrepreneurs and policy makers. Information can best be considered as a productive resource, potentially limiting and influencing the efficiency of production.

\section{RESEARCH METHODOLOGY}

\subsection{Description of the Study Area}

Gedeb-Hasasa District is located in West Arsi Zone of Oromia Regional State in Ethiopia, at about 335Kms SouthEast of the capital city Addis Ababa. According to the information from Agricultural and Rural Development Office (2011), the district has about 32 Keble's, among these 25 of them are rural based administrative with a population of 167,152 and 7 of them are under the town administration. 


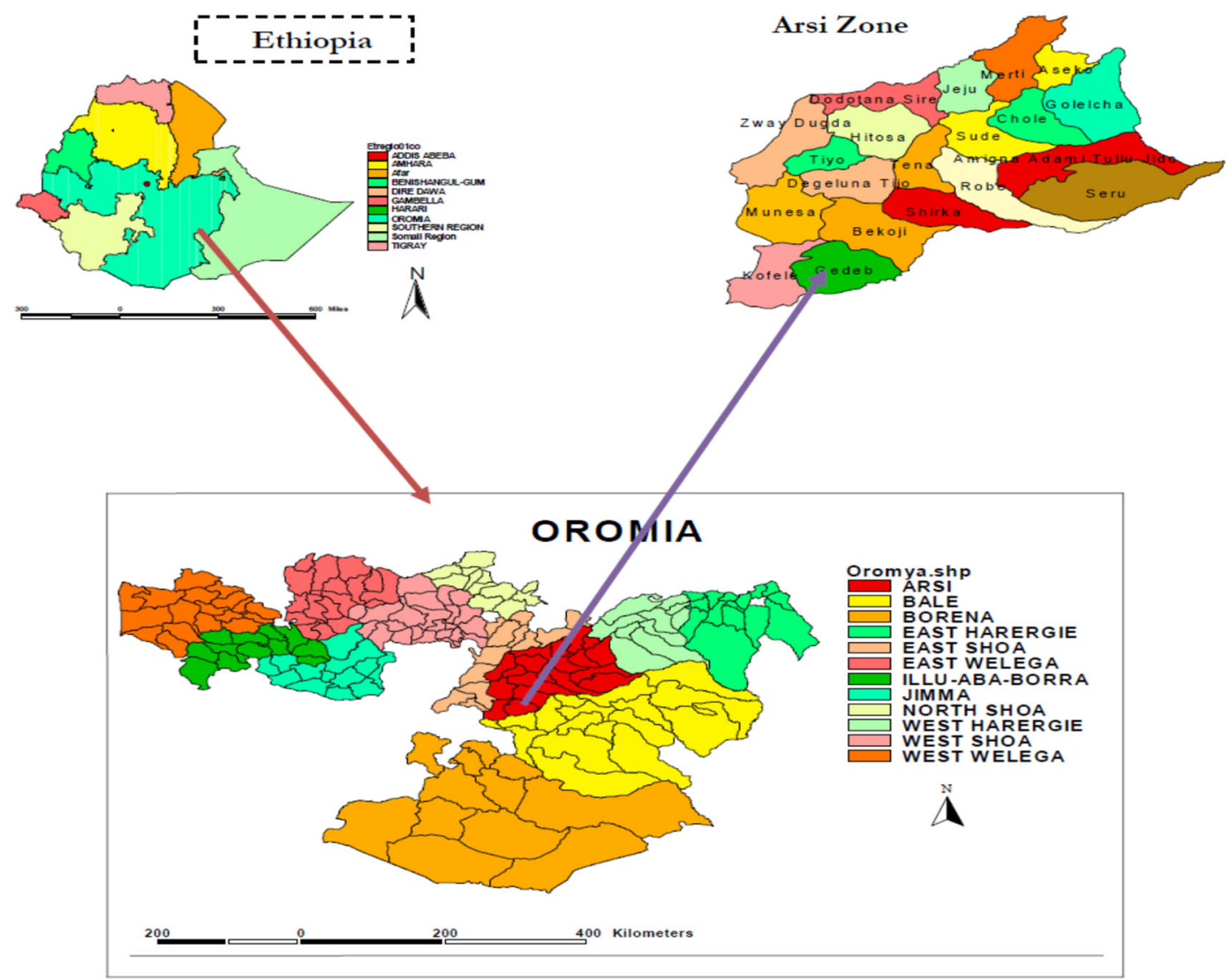

Figure 1: Maps of Ethiopia, Oromia, Arsi Zone and Study Area

Source: WARDO of the district

\subsection{Sample Size and Sampling Procedure}

The sample for the study is bread wheat producers of small householder's farmers in Gedeb-Hasasa District, West Arsi Zone, Oromia Regional State, Ethiopia. The district was purposively selected among the 12 districts of West Arsi zone of Oromia regional state, due to high production potential for different types of grain crops in general and wheat in particular, and due to the maximum available arable land for grain crops, specifically a large amount $(60 \%)$ of cultivated land was devoted for wheat production in the study area. On the basis of statistical random sampling techniques of probability proportional to size (PPS) 138 wheat grower farmers were randomly drawn from the list of farmers in each chosen four rural kebeles such as Walta'ii, Buchoo, Baatuu and Buburaa and 36, 28,40 and 34 respondents, respectively.

\subsection{Methods of Data collection and Analysis}

For this study, both primary and secondary data were collected and used, which were of qualitative and quantitative nature. Primary data were gathered by using pre-structured interview schedule from 138 sample households and Methods like Focused Group Discussions and key informants were used. Secondary data were reviewing different documents of District Office of Agriculture and Rural Development and other related articles. Finally, key informant interview and FGD was also used to support primary data. For this study, different descriptive statistical tools were employed to analyze the generated data. Statistical tools such as frequency, percentage, mean, max., min., SD, ranking technique, chi-square and F- value were used. Finally, Pearson's Product-Moment Correlation and Spearman Rho were employed to measure strength of relationships between dependent and independent variables. Karl Pearson's Coefficient of Correlation (r) were also applied to measure the degree of association or correlation between two variables measured quantitatively (Kothari, 2003. Statistical Package of Social Sciences (SPSS) and Microsoft Excel were used for analysis of data.

\subsection{Selection of variables and measurement techniques}

\subsubsection{Dependent variables:}

The dependent variables included in the study were access and utilization of information on WBPP. The indicators used in measuring the dependent variable were, frequency of access and utilization based on the interview schedule 
developed by the researcher. The levels of information access and utilization of the respondents were measured using the score given for respondents frequently access and utilization of information on recommended practices of bread wheat production package. Eight activities were identified and minimum and the maximum frequency score of 0 and 3 was given for each activity, respectively. This makes the minimum and maximum potential frequency score 0 and 24, respectively. However, the actual obtained minimum and maximum frequency score for information access was 1 and 22, respectively while the minimum and maximum score for information utilization was 1 and 20, respectively, which were taken as a base to categorize the sample households in to three $(1=$ low, $2=$ medium and $3=$ high) access and utilization of information.

\subsubsection{Independent variables}

For this study, 6 independent variables were selected and each of them was measured as follow.

Where,

AGE $=$ Age of respondents (Number of years -)

$\mathrm{EDU}=1$, illiterate, 2 , read and write and 3primary education, 4 secondary $(+)$

$\mathrm{ON}-\mathrm{FINC}=$ On-Farm Income $(\mathrm{ETB}+)$

OFFINC $=$ Off-Farm Income $(\mathrm{ETB}+)$

$\mathrm{SOP}=$ Social Participation $($ Score +$)$

$\mathrm{D}-\mathrm{Road}=$ Distance of farm from main road $(\mathrm{Km})$

D- Market $=$ Distance of farm from main market $(\mathrm{Km})$

$\mathrm{EXC}=$ Extension Contact (Score + )

MMEXP = Mass-Media Exposure $($ Score +$)$

\section{RESULTS AND DISCUSSION}

\subsection{The status of access and utilization information on recommended BWPP}

In relation to the status of access and utilization of information, analysis was made with respect to the eight identified recommended package for wheat production. Such as land preparation. Sowing time, improved varieties, weed management, seeding rate, fertilizer application, pest control and compost application are the recommended WPP in the study area. It's measured by frequency scores of access to and utilization of information by farmers $(0=$ Never, $1=$ sometimes, $2=$ Often and $3=$ Always $)$, respectively

\section{Land preparation}

Land preparation is one of the activities envisaged as a component of the package. According to the discussion made with the SMS of WARDO, three times land preparation is the recommended practice promoted by the district extension system. The survey results indicate that, most of the respondents accessed and utilized sometimes the recommended land preparation in the study area whereas; the least frequency of the respondent's information accessed and utilized always the recommended land preparation.

\section{Sowing time}

Sowing date generally depend on location, soil type, onset and distribution of rainfall and the variety to be used. Therefore, to the survey result indicates that, farmers in the study area, most of them had accessed information on sawing time but they did not utilized appropriately and they followed traditional sowing time rather than recommended once. As the result, the farmers were harvested low product.

\section{Seeding rate}

The research recommended and extension system promoted seeding rate for the area was $275 \mathrm{~kg}$ per hectare. The survey result shows that, most of the farmers were accessed recommended information on seeding rate practice, but their utilization is varying at different levels. This is due to lack of awareness, limited number of experts, technical application etc. were among the problem.

\section{Improved variety}

High yielding and disease resistant improved varieties are one of the recommended practices in bread wheat production package. The survey result indicates that, the irregularity pattern of access and utilization of improved variety of wheat seed among the farmers due to shortage of improved seed, high price of the varieties, mismatch variety with ecological area, types of variety available in the area and untimely availability of the seed in the study area.

\section{Fertilizer application rate}

Fertilizer rate vary from location to location depending on the fertility status of the soil, cropping sequence, varieties used and the input output prices. According to WARDO of the study district, currently applied fertilizer application rate practice was the previous blanket recommendation of $100 \mathrm{~kg} / \mathrm{ha}$ of DAP and $50 \mathrm{~kg} / \mathrm{ha}$ of Urea. The result of this study indicates that, as compared to the others, fertilizer application rate had highly frequency accessed among the farmers, but there was a variation among the respondents on utilization of the accessed information on recommended fertilizer application rate. This is due to high price (unaffordable price of input), lack of credit service, low number of suppliers, and untimely availability of an input were among the problem faced by the farmers. 


\section{Weed management practices}

Weed management can be facilitated by uprooting the weeds, plowing or harrowing. The recommended frequency of hand weeding in the study area is 2-3 times. The study revealed that, the respondents varies with regarding to their access to information and utilization of the accessed information on weed management. This is due to the reason that, the costs of chemical; unavailability and untimely availability of the chemical were among the most problems in the study area.

\section{Pest control practices}

The survey result shows that, recommended pesticide control practice access and utilized pattern of the respondents were varied. This implies that, accessed information did not fully utilized by the farmers of the study area. This is due to the reason that, FGDs revealed that since the frequency of pest incidence during last cropping season was hazardous and the demand of respondents have not match with the supply of pest control chemicals. In addition, farmers added the reason as to why they have not use herbicide and fungicide to control weed and disease in that it is too expensive and farmers cannot afford to pay for it as well as the chemicals are not available on time.

\section{Compost application rate}

According to the discussion made with the study district SMS, the recommended compost rate promoted by the extension system was 120 quintal per hectare. However, due to lack of awareness and its importance as well as use of recommended rate, the utilization level of compost by the farmers was very low as compared with other areas. This is due to the reason that, lack of experience, complexity of technical skill preparation, it was unfamiliar in the area, low demand or low interests of the farmers to utilized the packages.

Table 1: Frequency status of access and utilization information on recommended BWPP

\begin{tabular}{|l|l|l|l|l|l|l|l|l|l|}
\hline \multirow{2}{*}{$\mathrm{N}$} & Recommended & \multicolumn{3}{|c|}{ Frequency access to information } & \multicolumn{3}{l|}{ Frequency Utilization of information } \\
\cline { 2 - 10 } & Practices & Never & Sometimes & Often & Always & Never & Sometimes & Often & Always \\
\hline 1 & Land preparation & $16.7 \%$ & $50.0 \%$ & $30.4 \%$ & $2.9 \%$ & $27.7 \%$ & $51.1 \%$ & $16.8 \%$ & $4.4 \%$ \\
\hline 2 & Improved seed & $4.3 \%$ & $34.1 \%$ & $40.6 \%$ & $21.0 \%$ & $14.5 \%$ & $50.0 \%$ & $23.9 \%$ & $11.6 \%$ \\
\hline 3 & Sowing time & $4.3 \%$ & $26.8 \%$ & $43.5 \%$ & $25.4 \%$ & $21.7 \%$ & $34.1 \%$ & $31.2 \%$ & $13.0 \%$ \\
\hline 4 & Weed mgt & $0.7 \%$ & $38.7 \%$ & $36.5 \%$ & $24.1 \%$ & $32.6 \%$ & $35.5 \%$ & $18.1 \%$ & $13.8 \%$ \\
\hline 5 & Seeding rate & $10.9 \%$ & $31.2 \%$ & $40.6 \%$ & $17.4 \%$ & $18.4 \%$ & $36.8 \%$ & $32.4 \%$ & $12.5 \%$ \\
\hline 6 & Pest control & $2.2 \%$ & $20.3 \%$ & $38.4 \%$ & $39.1 \%$ & $13.8 \%$ & $51.4 \%$ & $26.8 \%$ & $8.0 \%$ \\
\hline 7 & Fertilizer appl & $2.2 \%$ & $24.6 \%$ & $37.7 \%$ & $35.5 \%$ & $18.1 \%$ & $31.2 \%$ & $24.6 \%$ & $26.1 \%$ \\
\hline 8 & Compost app & $39.1 \%$ & $37.0 \%$ & $14.5 \%$ & $9.4 \%$ & $47.8 \%$ & $36.2 \%$ & $13.8 \%$ & $2.2 \%$ \\
\hline
\end{tabular}

Source owned survey data, 2016.

\subsection{Identified Constraints of Access to Agricultural Information}

Constraints of access to agricultural information on bread wheat information package against their score and rank is illustrated in Table 32 below

Table 1: Constraints of information access on BWPP $(n=138)$

\begin{tabular}{|c|l|c|c|}
\hline No & \multicolumn{1}{|c|}{ Constraint of information access } & Freq. score & Rank \\
\hline 1 & Lack of awareness on existing sources of information & 120 & $1^{\text {st }}$ \\
\hline 2 & Inadequacy of facilities or professional & 110 & $2^{\text {nd }}$ \\
\hline 3 & Biasness of DAs & 106 & $3^{\text {rd }}$ \\
\hline 4 & Untimely provision of information & 51 & $4^{\text {th }}$ \\
\hline 5 & Lack of funds to acquire information & 25 & Rank \\
\hline No & Constraint of utilization of accessed information & Freq. score & $1^{\text {st }}$ \\
\hline 1 & Lack of credit services & 82 & $2^{\text {nd }}$ \\
\hline & Lack of money (Unaffordable price of inputs) & 79 & $3^{\text {rd }}$ \\
\hline 2 & Untimely delivery of agricultural inputs & 75 & $4^{\text {th }}$ \\
\hline 3 & Shortage of supplier's organization & 70 & $6^{\text {th }}$ \\
\hline 5 & Low level of education & 40 & $7^{\text {th }}$ \\
\hline 6 & Lack of interest by respondents & 25 & \\
\hline
\end{tabular}

\section{Source: Computed from own survey data, 2016}

As indicated in the above Table 2, the highest score was taken as the major constraint and the least score was taken as the minor constraint of access to and utilization of agricultural information. Based on this, the $1^{\text {st }}$ most important constraint was Lack of awareness, the $2^{\text {nd }}$ important constraint Development Agent bias, $3^{\text {rd }}$ Shortage of DAs, the $4^{\text {th }}$ Lack of interest by respondents, the $5^{\text {th }}$ constraint mentioned long distance of development agents' and PA administration office were the identified constraint to access information, respectively. Whereas, from the identified constraints to utilized accessed information on BWPP, the $1^{\text {st }}$ constraint pointed out by the respondents was shortage of credit. Followed the $2^{\text {nd }}$ important was untimely delivery of agricultural inputs, the $3^{\text {rd }}$ Unaffordable price of inputs, giving low attention to farmers' experience, the $4^{\text {th }}$ Non-existence of formal input 
supply institutions, the $5^{\text {th }}$ low level of education and the $6^{\text {th }}$ lack of interest of the respondents were the identified constraints to utilized accessed information on BWPP by the farmers in the study area, respectively.

\subsection{The association between access and utilization of AIs with independent variables}

The following table showed that all the variables viz., age, education, on-farm income, off-farm income, social participation, access to market, extension contact, mass-media expose and access to credit services toward Agricultural Information (AI) had a significant association with the level of information access and utilization of the farmers.

This was evident as majority of young farmers included in the study with high level of education were found to have more degree of availability and accessibility of ICTs as compared to old aged farmers with low level of educational qualification. The study also reported that farmers with higher level of income had higher purchasing ability of AIs. The higher degree of orientation of farmers towards outside the social system, exposed to massmedia, extent of extension participation and access of credit services also influenced the farmers to avail and access Agricultural Information (AIs). This implied that the variables included in the study had a significant association that led to the increase or less accessibility and availability of AIs among the farmers.

Table 2: Descriptive summary results of continuous explanatory variables.

\begin{tabular}{|c|c|c|c|c|c|c|c|l|}
\hline \multirow{2}{*}{ Variable } & \multicolumn{9}{|c|}{ Mean across access and utilization categories } \\
\cline { 2 - 9 } & \multicolumn{2}{|c|}{ Low } & \multicolumn{2}{c|}{ Medium } & \multicolumn{2}{c|}{ High } & \multicolumn{3}{c|}{ F Value } \\
\cline { 2 - 9 } & Access & Utiliz. & Access & Utiliz. & Acces & Utiliz. & Access & Utilization \\
\hline AGEHH & 44.56 & 47.50 & 45.92 & 44.43 & 44.84 & 44.59 & $16.44^{*}$ & $4.109^{* *}$ \\
\hline ONFINC & 22396 & 21809. & 19140 & 19742 & 19362 & 19379 & $15.86^{*}$ & $32.61^{*}$ \\
\hline OF-INC & 10738 & 8363 & 8217 & 9850 & 10361 & 10942 & $15.81^{*}$ & $10.90^{*}$ \\
\hline SOCIALP & 5.00 & 5.35 & 5.68 & 5.60 & 5.84 & 5.35 & $17.71^{*}$ & $8.10^{*}$ \\
\hline EXNP & 5.12 & 5.09 & 5.63 & 5.75 & 7.54 & 7.50 & $11.12^{*}$ & $5.87^{*}$ \\
\hline MAMIEXP & 3.02 & 3.29 & 3.23 & 3.57 & 5.68 & 4.97 & $9.95^{*}$ & $3.87^{* *}$ \\
\hline
\end{tabular}

Source: own survey data, 2016; $* *$ and $*$ significant at 1 and $5 \%$ probability Level respectively, NS= NotSignificant.

From the table, all the variables of age, annual on-farm income, annual off-farm income, social participation, extension participation, exposed to mass-media and access to credit services included in the study had a significant association with the access to and utilization of AIs among the farmers at $1 \%$ and $5 \%$ probability Level, respectively. With regard to usage of ICTs, it was found out that old aged farmers had lesser degree of usage of AIs when compared to young farmers. The study conducted by Haba (2004) in Rwanda reveals that, older farmers were less willing to get information than younger ones. Similarly, Katungi (2006), on his social capital and information exchange study in rural Uganda reveal that older men are less likely to engage in simultaneous receiving and providing of information, perhaps due to the low ability to communicate associated with old age. Since annual income of farmers was significantly associated with the accessibility of AIs, this implied that there would be increased usage among farmers with higher level of income. Research participants, viz., farmers included in the study also stated that the level of ownership and usage of ICTs was higher among farmers with better annual income. Further, it was also found out in the study that farmers with higher degree of exposed to mass- media, social participation, extent of extension participation and access to credit services had higher degree of utilized AIs. This finding is in agreement with the study conducted by Asres (2005).

Table 3: Descriptive summary results of dummy/categorical explanatory variables

\begin{tabular}{|l|l|l|l|l|l|l|l|l|}
\hline \multirow{2}{*}{ Variable } & \multicolumn{6}{l|}{ Proportion across Access and utilization categories } & \multicolumn{2}{l|}{$\chi$ 2-value } \\
\cline { 2 - 9 } & \multicolumn{2}{|l|}{ Low } & \multicolumn{2}{l|}{ Medium } & Access & Utilize \\
\cline { 2 - 9 } & Acces & Utiliz. & Access & Utiliz. & Acces & Utiliz. & & \\
\hline Credit access & \multicolumn{2}{|c|}{ Low } & \multicolumn{2}{|c|}{ Medium } & \multicolumn{2}{c|}{ High } & & \\
\hline No & 10.9 & 8.7 & 15.2 & 15.2 & 8.00 & 7.2 & & \\
\hline Yes & 8.8 & 15.9 & 31.2 & 37 & 18.8 & 15.8 & & \\
\hline Total & 19.7 & 24.6 & 43.5 & 52.2 & 26.8 & 23 & $13.60^{* *}$ & $9.20^{* *}$ \\
\hline
\end{tabular}

Source: own survey data, 2016. $* *$ and NS significant at $1 \%$ probability Level and, NS= Non-Significant respectively.

\section{Conclusion and Policy Recommendations}

In relation to the status of access and utilization of information, analysis was made with respect to the eight identified recommended package production practices. In view of that, respondents were categorized in to three groups as low, medium and high on the basis of access and utilization by using mean with standard deviation. With this analysis, majority of the respondents $(43.5 \%)$ were in the medium group of access category and the others 
$29.7 \%$ in low and $26.8 \%$ were in higher category, respectively. Whereas majority of the respondents $(52.2 \%)$ were also in the medium utilization category and for low and high categories were $24.6 \%$ and $23.2 \%$, respectively. Therefore, access and utilization level of the majority were observed to be in the medium level.

The study also reviewed that, there is the variation on access to and utilization of agricultural information on wheat production components among the sample respondents. To this end, Result of different descriptive statistical analysis indicated that, fair numbers of the hypothesized variables were significantly related with farmers' access to and utilization of agricultural information. The variables such age of the household (AGEHH), on-farm income (ONFINC), off-farm income (OF-INC), social participation (SOCIALP), access to market (ACCTMKT), access to credit services (ACCRED) and access to extension services (EXTP) were significant relation with access and utilization of agricultural information on bread wheat production package at less than $1 \%$ and $5 \%$ significance level respectively. Except age of the household, all variables were shown positive relationship with dependent variables. However, the study has found that Lack of awareness, Shortage of DAs, Lack of interest by respondents, Distance from institutions, lack of training and practical exposure were the major constraints faced by the farmers to access AIs. Whereas, Lack of credit services, Lack of money (Unaffordable price of inputs), Untimely delivery of agricultural inputs, Shortage of suppliers institution and Low level of education were also the major constraints faced by the farmers in the effective use of ICTs. Since there is an increased penetration in the level of availability and accessibility of ICTs among the farmers of the district, there is a need to ensure that the problems of the farmers are being met in order to enable the farming community derive maximum benefits on better access to information services through the use of ICTs for agriculture and other developmental purposes. Thus, this study was conducted to indicate some policy directions to improve the livelihood of smallholder of wheat producer farmers in the study area Based on the findings of the study; the following recommendations were also made:

i. Better to strength farmers Participation in different extension events especially in demonstration, field day and training so as to improve farmers' access to information and effectively utilizing could be recommended. Furthermore, Extension system should have to change its view to innovation system to boost agricultural information for the farmers with in a collective action

ii. The development of ICTs has facilitated the dissemination of knowledge and information and it is revolutionizing the use of technology in agricultural production and provision of market information to maximize the returns to agriculture would be recommended.

iii. The rural development strategy should give priority attention to promoting on-farm diversification technologies; use intensive farming practices through providing sustainable technical training and linking basic education with technical training for small household farmers

iv. Government should have to form suitable environment to link the farmers with information technology to provide improved ICT extension services to uplift the socio-economic status of the farmers and the rural people.

v. More awareness-cum-training programmes on ICT should be encouraged among farmers by district agricultural departments, research organizations and its allied departments in order to increase the confidence, competence and skill in using ICT for development.

vi. To Increase engagement in social participation, extension participation and social media among rural farmers on farming should be recommended in order to enhance the communication pattern among themselves and extension personnel

\section{Conflict of Interest}

The authors would like to declare that there is no interest of conflict and we want to disclose you that it is our original research work.

\section{REFERENCES}

Achugbue, E. I., \& Anie, S. O. (2011). ICTs and Information Needs of Female Farmers in Delta State, Nigeria. Library Philosophy and Practice (e-journal) paper 448.

Babu, S.C. and Govindarajan, S.K. (2011). Farmers Information Needs and Search Behaviors. Case Study in Tamil Nadu, India, Report for International Food Policy Research Institute, Washington, DC.

Bachhv, N.B. (2012). Information needs of the rural farmers: A study from Maharashtra, India; A survey, Library Philosophy\&Practice,Availableathttp://digitalcommons.unl.edu/cgi/viewcontent.cgi?article=2043\&context= libphilpra.

Bekele, M. (2008). Information Sharing and Utilization among farmers: The Case of Maize Package in Mettu Woreda, Oromiya Region, Ethiopia. M.Sc. Thesis (Unpublished) Presented to School of Graduate Studies, Haramaya University.

Byamugisha, H. M. Ikoja-Odongo, R. Nasinyama, G.W. \& Lwasa, S (2008). Information seeking and use among 
urban farmers in Kampala district, Uganda, Agricultural information and IT proceedings of IAALD AFITA. 24 to 27 August 2008, Tokyo University, Japan.

Collence .T. (2012). Knotting and networking agricultural information services through Web 2.0 to create an informed farming community. World Library and Information Congress: 8th IFLA General Conference Harare, Zimbabwe, 24 May 2012.

Daniel, T. (2008). Access and Utilization of Agricultural Information by Settler Farming Households: The case of Metema Woreda, North Gondar, Ethiopia. M.Sc. Thesis (Unpublished) presented to Haramaya University.

Daudu, S. Chado, S.S. \& Igbashal, A. A. (2009). Agricultural information sources utilized by farmers in Benue state, Nigeria, Publication Agriculture and Technology, Vol.5 (1), 39- 48 . Available at http://patnsukjournal.net/Vol5No1/p5.pdf.

Ebrahim, M. (2005). Extension Experiences in Ethiopia. Paper Presented in the IPMS Workshop on Introduction to Research and Development for Innovative Extension System held from May 23-25, EARO, Addis Ababa, Ethiopia.

FAO (Food and Agriculture Organization). 2011. FAO Global Information and Early Warning System on Food and Agriculture. GIEWS Special Report.

FAO (Food and Agriculture Organization). 2014. Food Balance Sheets. Rome: FAO. Accessed at http://faostat.fao.org/site/368/DesktopDefault.aspx?PageID=368\#ancor.

Ferris, S. (2005). Developing market information services in Eastern Africa: the food net experience, local, national and regional market information services. International Institute of Tropical (IITA), Ibadan Nigeria.

Gundu, M. (2006). The Impact of the Level of Literacy on Access to Information by Urban Black Women at Kariba, Zimbabwe. Unpublished Honors Paper, Zimbabwe.

IFPRI-World Bank. (2010). Gender and Governance in Rural Services: Insights from India, Ghana, and Ethiopia. Agriculture and Rural Development. Washington, DC, USA: The World Bank.

Jemal, K. (2010). Access and Utilization of Agricultural Knowledge and Information by Women dairy Farmers in Ada'a district, Oromia Regional State, Ethiopia. MSc. Thesis, Haramaya University, Haramaya, Ethiopia.

Katungi, E.( 2006). Gender, Social Capital and Information Exchange in Rural Uganda IFPRI and Melinda Smale. IFPRI (International Food Policy Research Institute) CAPRi Working Paper No. 59, University of Pretoria, Uganda.

Khan, S.A. (2005). Introduction to Extension Education in Memon, R.A. and E. Bashir (eds.). Extension Methods (3rd ed.). National Book Found, Islamabad, Pakistan.

Lwoga, E. T., Stilwel, C., \& Ngulube, P. (2010). Access to and Use of Information and Knowledge for Agricultural Development. IN: SCECSAL X1X Botswana, Enhancing Democracy and Good Governance through Effective Information and Knowledge Services. Proceedings of the 19th Standing Conference of Eastern, Central Southern Africa Library and Information Associations (SCECSAL).

Mtega, Wulystan P. (2012). Access to and usage of information among rural Communities: a cases study of Kilosa District Morogoro Region in Tanzania. Volume 7, No.1, the Canadian journal of Library an information Practice and Research.

Murithii. (2009). Information Technology for Agriculture and rural development in Africa: Experiences from Kenya. Paper presented at the conference on International research on Food Security, Natural Resources Management and Rural development, Tropetag, University of Hamburg, Kenya.

Odini, C. (2014). Information seeking and communication behaviour of Kenya small-scale farmers. University of Dares Salaam Journal Vol.7, No.2

Okwu, O. J., \& Daudu, S. (2011). Extension Communication Channels' Usage and Preference by Farmers in Benue State, Nigeria. Journal of Agricultural Extension and Rural Development, 3 (5), 88-94.

Rashid, S. (2010). Staple Food Prices in Ethiopia. A paper prepared for the COMESA policy seminar on "Variation in staple food prices: Causes, consequence, and policy options”, Maputo, Mozambique, 25-26 January 2010, under the African Agricultural Marketing Project (AAMP).

Tologbonse, D. Fashola, O. \& Obadiah, M. (2008). Policy Issues in Meeting Rice Farmers Agricultural Information needs in Niger state, Journal of agriculture extension, vol.12 (2), Available at ajol.info/index.php/jae/article/view/47053/33437.

UN Development Programme (UNDP) (2011), Human Development Repo rt 2011, available at: http://hdr.undp. 
org/en/media/HDR_2011_EN_Complete.pdf (accessed 27 November 2012).

US State Department (2012), "Ethiopia country profile", available at: www.state.gov/r/pa/ei/bgn/2859.htm (accessed 27 November 2012).

Yealembirhan. (2007). Integrating the Formal and Informal Wheat Seed Supply Systems to Improve Farmers' Access to Modern Cultivars in the North Shewa Zone of the Amhara Region, Ethiopia. M.Sc. Thesis (Unpublished) Presented to School of Graduate Studies of Haramaya University, Ethiopia. 